also arranged to use with this lens, just before second contact, an objective prism forming a spectrum upon necessitated a second tube 135 feet long inclined at about 8 degrees to that used for the direct photographs of the corona. Both tubes were made of thick Can-
ton flannel and were 42 inches square with diaphragms ton flannel and were 42 inches square with diaphragms
of progressively increasing size 10 feet apart. The two of progressively increasing size 10 feet apart. The two
tubes were fastened to trestle work covered by long anvas tents. Nearly one thousand yards of canva small photographic house which had been prepare in sections and was transported from Washington to Sumatra. Besides the great horizontal telescope
5-inch, 38-foot lens was also used for obtaining inner coronal photographs. This lens was mounted upon a pole in such a manner as to be in line with the sun
prom the eastern window of the photographic house Prom the eastern window of the photographic hous
at the moment of totality. A conical tube of whit at its lower end, ran from the house to the lens, but was not attached to the lens or its housing. There being thus no provision for following the apparent motion of the sun with the lens, a suitable motion was
given to the photographic plates by means of a clock. With this instrument 11 by 14 -inch plates were em.
ployed. Upon an instrument which carried the 18-inch ployed. Upon an instrument which carried the 18-inch
mirror of the horizontal telescope was mounted equaprovided with a conical tube, so that a considerable field was covered. A shade glass, opaque to violet
light, was placed over this lens. The purpose of the shade glass was to enable a comparison to be made
between the form of the outer corona as photographed with yellow and green light and as photographed with Within the eastern part of the shed there was mounted upon an improvised polar axis a collection
of four cameras well provide as to moving gear by being connected with the very accurate spectro-barom being connected with the very accurate spectro-barom.
eter clock. These cameras were two similar pairs,
one with short focus and the other with long focus lenses. The former were two landscape lenses of $4 \frac{1}{2}$ inches aperture and 40 inches focus, each provided
with a 30 -inch square plate. In front of one lens was with a 30-inch square plate. In front of one lens was
placer a shade glass opaque to violet light. The two
long-focus lenses were of 3 inches aperture of 111 feet focus and resembled those recommended by Harvard research for a possible intramercurial planet. The axes of these two cameras were inclined so that to-
gether they covered a space east and west of the sun about 12 degrees by 28 degrees in extent. Their fields of a single plate 24 by 30 inches. \section{THE UTILITY OF ALKALINE PHOSPHATIC}

By JoIn Hugines, F.I.C.

Bewore considering the subject included under the title of this paper, it will be desira
to the origin and progressive use of

The manufacture of superphosphate in this country may be said to have commenced in 1842 , when the ent for treating finely-ground mineral phosphates, such acid. The chemical theory then put forth maintained that the agricultural value of phosphatic manures de pended upon the extent to which the phosphates they contained were rendered soluble in water through the
aid of acid. It was conterded that this solubility in water effected the most complete diff usion through the
soil that could possibly be obtained, and the theory in restricted to soils containing plenty of lime, so that the acidity of the manure may be immediately absorbed by alkali in the soil. Indeed, at first, sulphuric acid being expensive, it was only used in small pro portion, and great caution was observed in the mixing
arrangements. Only a portion of the phosphates in
the coprolites was rendere soluble in water, amount ing perhaps to 20 per cent in the manure produced, and form of insoluble or undissolved phosphate of lime. Consequently, in those days, superphosphate was sen contribute very materially to increase the sale an render the new manure popular among farmers, for
there were never any complaints about the damp acid condition of the manure.
When acid, however, became cheaper as the result of improved manufacture from less costly materials, original patent rights, sulphuric acid was added in greater quantity, and the utmost possible amount of soluble phosphate was obtained, so that only 2 or 3
per cent of phosphate of lime was left in a condition Superphosphate then became damper and more acid so that complaints respecting its bad condition were of Superphosphate when first introduced was chiefly applied as a manure for turnips and swedes raised on good arable land containing sufficient lime, yet there appears to have been some doubt raised in the mind of so keen an observer and experimentalist as the lat
Dr. Augustus Voelcker. F.R.S., as to whether acid manures were not conducive to disease in these roots
At any rate, as early as 1863 we find him writing At any rate, as early as 1863 we find him writin
in the Journal of the Royal Agricultural Society upo "Phosphatic Manures for Root Crops" as follows: different practical effect on different soils.

"Purely mineral superphosphates fail to produce good turnip crops on light sandy soils

use of superphosphate, however beneficial it may be the complete or partial failure or the presence of to ease in the turnip crop.
"No acid combination as such can enter into plants without doing them serious damage; even free vege-
table acids, as humic and ulmic acils, are injurious to table acids, as humic and ulmic acids, are injurious to
all crops cultivated for food for the use of man or beast; and unless these acids, which are always present in what practical men call sour humus, are neutralized most innutritious herbage can be grown.

"Free mineral acids are, I believe, still more injurious to all farm crops, and perhaps to ail plants, than "A very dilute solution of sulphuric acid-say one part in 1,000 of water-may be used with advantage quartz sand; after one or two applications, the weeds will be destroyed and will not reappear for a long time.
But if the walks are male with limestone gravel, the application of a much stronger acid has little or no effect on the grass or weeds; after some time the latte seem to grow all the better for having had a taste
of dilute sulphuric acid. In reality, however, no acid enters these plants, but on coming into contact with
the limestone gravel unites with the lime to form that useful fertilizer, sulphate of lime or gypsum. "These examples thus prove unmistakably that a soil
which contains free acid, in ever so small a quantity, is unfit to maintain a healthy growth.

"We have, therefore, strong presumptive evilence strongly acid character, does not as such enter roots of plant

"The reconversion of soluble into insoluble phos-
phate, perhaps may appear undesirable, but in reality. the healthy and luxuriant development both of turnips and all other crops to which superphosphate is applied. phate in commercial superphosphates and turnip manures, is precipitated and rendered insoluble in the soil crop." resent the views of one who was rightly regarded a an authority upon the properties and use of artificial which these views have been realized in actual farm practice during succeeding years.

In 1875 , the Aberceenshire experiments with finely ground phosphates were instituted and conducted
under the management of Prof. Jamieson for some tears. The publication of the results excited much in ments that insoluble, or more properly termed undis ments that insoluble, or more properly termed undis tion and in sufficient quantity, possessed very con
siderable fertilizing value, whereas. according to the previously held theory, such raw phosphates were sup posed to possess no practical manurial value.
Further, these experiments proved that on certain was not superior in its action as a manure to undis solved phosphates to anything like the extent that has hitherto been generally supposed.

Very naturally these novel results, being opposed
to the theory hitherto held, excited a corsiderable amount of hostile criticism, which, however, time and more extended experience

The experiments were carried out at five stations situated in different parts of the county of Aberdeen and the soils are describe in the official report as and the analyses show that in every case they were specially deficient in lime. The figures for lime at
these five stations were respectively $0.08,0.17,0.21,0.33$ and 0.38 per 100 parts of the dry soil. soluble phosphate as supplied by superphosphate would not be likely to exert its full benefit, while the vegetable acids existing in the black mould wciuld naturally considerable extent. In short, the conditions were most favorable to the action of undissolved phosphates, uble phosphates.

themselves, were, however, distinctly useful both scientifically and practically, an what must now be regarded as a step forward in th economical application of finely-ground neutral phos phates.

About the year 1883 the now well-known basic slag or Thomas phosphate powder was introduced to the
agricultural world. It is the residual slag resulting from the treatment of iron ore by the Thomas-Gilphosphate of lime and basic silicate of lime, associated with some iron, manganese and magnesia compounds. It has a distinctly alkaline character, but it is a mis
take to suppose that this material contains any con siderable quantity of free lime. because any such ex cess of lime would indicate a wasteful method of manufacture, lime being only arlderl in sufficient quantity to
remove the phosphorus and silica existing in the original iron ore.
Though but slightly soluble in cidinary water it dissolves to a certain extent in water impregnated with cids which exist in sour grasis that largely contribut to make its application so beneficial on certain kinc No other manure has ever before occasioned so grea a diversity of opinion as to its value as a fertilizer.
When finely ground and applied to suitable land with sufficient. water either in the soil or from rainfall, the results have been most satisfactory, both in the in creased yield and in the improved quality of the gras
and hay: but where the conditions are unfavorable and the land unsuitable, the results have been most disa pointing. Indeed, when first introluced agricultura
chemists of high repute were disinclined to place any fertilizing value on such a hard fused mass, howeve finely it might be ground. because it was so insoluble
Little by little, however, farmers were induced to
take small quantities for trial, chiefly on old and sour grass lands, and the practical results were so good on - that scientific authorities were soon compelled to recognize its value, and as the market price was low
the material naturally became popular in certain localiIn this country the importance of fine grinding has hitherto been recognized as the chief test of the probner, of the Agricultural Station of Darmstadt, has insisted upon the solubility in a 2 per cent solution of
vegetable acid, such as citric acid, as a further and more definite test of probable manurial value. Dr. Bernard Dyer, in his paper "On the Determina-
tion of Probably Available Mineral Plant Food in Soils" tion of Probably Available Mineral Plant Food in Soils"
(Journal of the Chemical Society, 1894), has adopted a cold 1 per cent solution of citric acid for determining
the portions of phosphoric acid and potash existing in a presumably available form in the soil. a presumably available prest writer, however, has selected as his
standard solvent a 0.10 per cent cold solution, consist-
ing of 1 part of citric acid to 1,000 parts of cold distilled ing of 1 part of citric acid to 1,000 parts of cold distilled water. Such a solution is twenty times weaker than
that of Prof. Wagner, and ten times weaker than that of Dr. Dyer.

In fact, it represents an acidity absolutely below that of the sap of any of the 103 plants, examined by Dr. approximates to the natural acidity of ordinary soils ployed.

It is therefore contended that any phosphoric acid, lime or potash dissolved out by this standard solution,
may be fairly regarded as existing in a form available as plant food, whether is a soil or in a manure. In the following table the relative solubility in this standard solution of five different kinds of finelyground raw phosphate, is compared with that of a good specimen of basic slag.
In each case, one gramme of the ground phosphate was exhausted with 1.000 grammes of cold distilled
water, in which one gramme of $r$ 'ystallized citric acid After starding 24 hn:is with occasional stirring
the insolu'sle portion: was filtered off, ignited and the insclu'sle portinn was filtered off, ignited and
weigheri, while thr nroportions of lime and phosphoric
acid were dete:mined in the clear solution. MINER.AL PIIOSPII ATES. risubility in cold weak solution of citric Acid (1 :

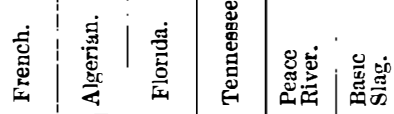

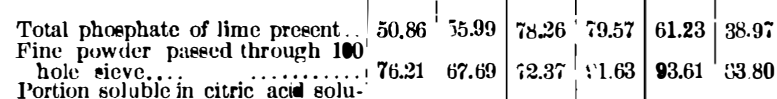

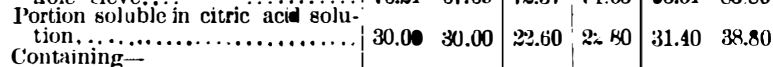

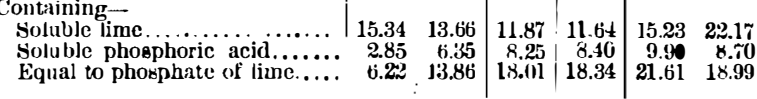

The above results show the percentage of phosphate of lime present in the respective samples, also the in :-
ness of the grinding, the extent to which the respect ve ness of the grinding, the extent to which the respect ve
specimens were dissolved by the cold, weak citric
acid solution, and finally, the proportions of lime and phosphoric acid in its equivalent of phosphate of lime existing in the cold citric solution.
It will be seen that ground phosphates are only sol uble, and therefore available as plant food to the ex.
tent of 22.60 to 31.40 per cent, and that the basic slag is only dissolved to the extent of 38.80 per cent, in
fact only a little more than one-third of its weight,
though it was of good quality, 38.97 phosphate of lime and 83.80 fineness.

As regards the actual amount of phosphate of lime with a fineness of 93.61 , gave the highest figures for solubility, there being 21.61 phosphate of lime dissolved In the case of basic slag, the figures, though rela tively higher, are actually less, namely, 18.99 phos pesults explain why Prof. Jamieson, with the black vegetable mould to experiment upon, obtained an ap-
preciable increase in the yield of turnips from the ap-
plication of finely ground raw phosphates, though if we take the most favorable example, namely, Peace
River, only about one-thir of the total phosphates River, only about one-third of the total phosphates
would have been utilized as available plant food and
the remaining two-thirds was of no use to the crop. The defect in the economical application of finely is this want of solubility that is the defect also of basic slag when applied to many soils.

Before leaving these figures it is interesting to notice that it is only in the proportion of soluble lime that basic slag shows a superiority over that of Peace
River phosphate, there being 22.17 per cent dissolved out as against 15.23.
Indeed, the fertilizing value of ordinary basic slag must be ascriber as very largely due to the ready sup ply of lime when the slag is brought in contact with the soil or from the rainfall.
tour

It is well known that slag fails to produce any
practical results on certain soils, and this failure is probably due partly to a deficient supply of water an partly to the absence of TIIE NEW MANTTE BASIC ST PERTIOSTIATE.

It occurred, therefore. to the author, after careful useful manure could be producerl by the careful admix ture of sultable proportions of ordinary acid super After making numerous trial mixtures the mos After making numerous trial mixtures the most
suitable proportions were decided upon, and a manure 
basic chareter, and at the same time supplied from soluble in the standard solution (1 in 1,000) of citric acid. The manure so produced was appropriately called basic superphosphate because it combined the alkalin nature of slag with the well-known solubility of superThe mechanical condition is superior both to that of basic slag and superphosphate. Compared with the so that if equal weights be placed in two glass tube about 1 foot long basic superphosphate will be found to occupy a space of 11 inches as compared with only
$41 / 2$ inches occupied by basic slag, the relation in round

Compared with superphosphate the new material moisture insteal of the 14 to 18 per cent usually found in commercial superphosphate. Being in a finely ground dry powder of light weight
ad bulky nature, greater uniformity and more perfect distribution can be obtaine than is possible with basic slag, which when sown by hand is apt to drop be-
tween the fingers before complete delivery can be efFarmers will appreciate these advantages, and will any clogging of the drill from damp condition, which in the case of badly made superphosphate is a very the manure quite impossible.

The general composition of basic superphosphate COMPOSITION OF BASIC SUPERPHOSPHATE.

Moisture (lost at 212 leg. F.)

Combined water and loss on ignition.

Lim

Sulphuric a

Oxides of iron, alumina, magnesia, etc.. 28.50

*Equal to phosphate of lime......... 29.68

The manure usually contains from 33 to 35 per cen of total lime, so that in this respect basic superphos-
phate supplies fully 10 per cent more lime than ordiphate supplies fully 10 per cent more lime than ord-

The superior solubility in cold water of basic super phosphate compare with good basic slag, containing in the foliowing table:

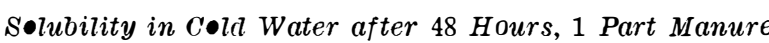
to 1,000 Parts Cota Water. Basic Basic Basic Basic
Super. Slag.

\begin{tabular}{llr} 
*Portion soluble in cold water.. & 66.80 & 6.60 \\
Portion insoluble (afterignition) & 33.20 & 93.40 \\
\hline
\end{tabular} $\overline{100.00} \overline{100.00}$

Containing$\begin{array}{rr}22.28 & 4.70 \\ \text { None None }\end{array}$

Phosphate of lime ............. None None

It will be seen that basic superphosphate is fully ten times more soluble in perfectly cold water than well
ground basic slag, the figures being 66.80 against 6.60
per cent. Further, that there is 22.28 lime dissolved out in the former against only 4.80 in the latter. These figures may, perhaps, explain why basic slą fails on certain soils, while it produces excellent re-
sults upon others. It is not ordinary water that is capable of decomposing a hard fused mass like slag. however finely it may be ground, but water impregon sour acid soil that special benefit may be expected from the application of slag.

It will be notice that no phosphate of lime was dissolved out by plain water from either manure, be-
cause on account of the presence of lime in excess, all cause on account of the presence of lime in excess, al
the phosphate of lime was retained in a precipitated form in the basic super, and in a more insoluble form

$\bullet$ lubility in (1 in 1,000) Citric Acid Solution (1 par Basic Basic

*Portion soluble in citric solu- Super. Slag.

tion $\ldots \ldots \ldots \ldots \ldots \ldots \ldots$
Portion insoluble (after ig-

$\overline{100.00} \overline{100.00}$

*Containing-

$\begin{array}{lrr}\text { Soluble lime } \ldots \ldots \ldots \ldots \ldots & 34.73 & 22.17 \\ \text { Soluble phosphe ic acid......... } & 12.45 & 8.70 \\ \text { Equal to phosphato of lime.... } & 27.18 & 18.99\end{array}$

The above figures show that when both manures were treated in exactly the same manner, in regard to the same time allowed in each case for exhaustion with the standard solvent, basic super was dissolved cent in the case of the basic slag. Further, 34.73 lime was dissolved in the former, against 22.17 in the latter. Lastly, 27.18 phosphate of lime was dissolved
The slage emplic super, against 18.99 out of the slag.
The the same as was use in all ihe previous experiments, and was of good quality and phosphate of lime, only 18.99 , or less than half, was dissolved by the standard solvent, and may therefore
be considere to represent the proportion probably available as plant food

It is very important to bear these figures in mind and to remember that it is not the total amount of garded as indicative of its manurial value, but the actual quantity that is likely to be available as plant

Hence, as a quick-acting manure, suitable for lat application in the spring, basic super must be re
garded as far superior in fertilizing effect to ordinary slag, notwithstanding the high total contents of phosphate of lime contained by the latter.

THE UTILITY OF THE NEW MANURE.

Basic superphosphate can be applied, indeed has
been applied in the season of 1901 , with great ad vantage on soils deficient in lime, such as sand, gravel, Briefly, it may be

Briefly, it may be stated that all soils containing by the application of basic superphosphate instead of slag or ordinary superphosphate.

It is of practical importance to state that though
originally invented to supplement the bility of slag, which is fully recognize by those in terested in its sale (they therefore recommend its application during the winter months), it has been
found by actual field results that the new manure is superior also to superphosphate on soils deficient in

Mr. William E. Bear, of Magham Down, Hailsham, employing equal quantities of basic super and ordinary ishes, 66 per cent greater in weight by the use of the ormer manure, than he did by the latter.

Bernard Dyer's analysis, only 0.68 , according to $\mathrm{Dr}$ iny state. In another experiment on the farm of Mr. Ouston, rate of 5 cwt. per acre, gave a specially good crop, 0.78 of lime per cent.

Mr. Edward Packard, at Saxmundham, obtained by $18 \%$ tons of swedes, against 15 tons produced by 5
then the soil in this case containing 1.75 lime per cent.
It is well known that soils subject to the disea known as finger and toe in turnips, are naturally deficient in lime, containing in fact considerably less suppose that an alkaline phosphate manure would nhosphate manure such as superphosphate.
During an acid

During the season of 1901 numerous instances were
recorded in which basic super has been used on such recorded in which basic super has been used on such
soils with very marked advantage, the virulence of
the disease being materially reduced, and in some remarkable cases in Scotland, its application has com pletely prevented any attack, while other parts of the
field manured with ordinary superphosphate had suffered very much from the disease.

In connection with this subject, it may be convenient to point out by means of the following tabulated fig ures, the relation in which lime and phosphoric acid
are respectively removed from the soil by ordinary farm crops.

LIME AND PHOSPHORIC ACID REMOVED PER ACRE BY FARM CROPS.

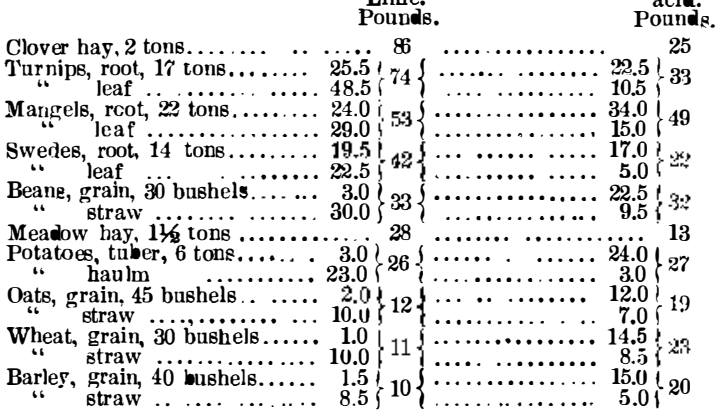

It will be seen that in respect of an average crop of clover, hay, turnips, mangels, and swedes, lime is rela acid. It is useless, therefore, to expect to grow good
crops, or crops free from certain diseases, if there is deficiency of lime.

On the other hand, it would appear that wheat, bar ley and oats require phosphoric acid in greater promuch less than in the case of root crops or clover hay. This table of figures is also useful in illustrating the
great waste of applying lime in large quantities, such great waste of applying lime in large quantities, such as 3 or 4 tons per acre, for the actual crop require-
ments would appear to be less than 100 pounds per If 2 or 3 hundredweight of superphosphate are con sidered sufficient to supply the requisite quantity of should be sufficient to supply the requisite quantity of lime. Of course this remark only applies to the applica tion of lime to ordinary well-drained soil, and not to soil would require larger dressings of lime.

But under ordinary conditions large dressings of lime are practically wasted because the slaked lime which is not absorbed by the soil or the plant, rapidly becomes converted into carbonate of lime, in which Iorm it is but little soluble in ordinary water.
Usually where the soil is deficient in lime, the cost of its application js very great by reason of carriage
from a distance, and in all such cases basic superphosphate will be found particularly useful and decidedly economical, because in addition to supplying from 25 to 27 per cent of phosphate of lime in a for'm suffi-
ciently soluble to affor available plant food, 'it also supplies an appreciable dressing of caustic lime. How beneficial small dressings of alkaline ashes
are may be inferred from the practice in India of burnare may be inferred from the practice in India of burn
ing the stubbles after the removal of the corn and ing the stubbles after the remov
previous to the usual rainfall.

In this country the custom of collecting and burning the common couch grass (Triticum Repens) is to be way of eradicating this troublesome weed, but as bein a cheap means of supplying valuable alkaline ashes to the soil; for these ashes materially assist that im-
portant bacterial action whereby the inert vegetable matter of the soil is converted into valuable fertiliz ing compounds such as nitrates. A strong argument in favor of the utility of alka-
line phosphatic manures is afford by the fact that all the natural manures hitherto used in agriculture are distinctly alkaline. Thus, farmyard manure, in alkaline, and its agricultural value depends upon the extent to which the nitrogen compounds are conextent to which the nitrogen compounds are con-
verted by proper fermentation into ammonia salts.
Guano, especially the good old Chincha Peruvian quality, is thoroughly ammoniacal.

Bone dust, dried blood, woolen waste and shoddy, also soot, and lastly lime, are all more or less alka-
line in their nature, and certainly not acid. Moreover, it is hardly necessary to repeat that alkaline phosphate of lime as a manure for certain soils.

Indeed it is not natural that manures should be acid, and the reason why ordinary acid superphosphate has been beneficial to crops grown on good arable land, is that the acidity of the manure has been ab-
sorbed or neutralized by the abundance of lime usually

Obviously, where the soil is deficient in lime the acidity of superphosphate cannot be immediately ab-
sorbed, and harm may be done to the young rootlets of the plant.

It would require a very heavy dressing of lime to saturate the soil so completely that every square inch
of surface should always contain the necessary quan. of surface should always contain the necessary quan.
tity of lime requisite to absorb the acid from every with it. In other words, it is much more economical to add lime in small quantity to the manure for the
purpose of immediate and complete neutralization, than to add lime in large quantities and at long inter vals to the soil in order to provide a wasteful excess
of alkali for the absorption of a minute quantity of of alkali for the absorption of a minute quantity of
acid. The necessity of relying upon a sufficiency of lime in
the soil is entirely removed when using basic superphosphate, as by the careful admixture of an excess of phosphate, as by the careful admixture of an excess of
lime in its manufacture all acidity is removed and
the manure may be applied, mixed directly with the the manure may be applied, mixed directly with the As a practical demonstration of the injurious effects produced by the continued annual application of acis Woburn experiments by Dr. Voelcker in the last number of the Journal of the Royal Agricultural Society,
in which a photograph is given of absolutely barren spots where the barley crop had entirely failed in con-
sequence of the annual application of sulphate of ammonia to a ferruginous sandy soil. These barren spots were evidently due to the local accumulation of acid the adjoining plot, which had received the same quantity of ammonia salts annually, but had in addition re-
ceived a dressing of lime, the barley was looking thoroughly healthy.
On such soils as that at Woburn, basic super, which, in addition to phosphates, supplies some caustic lime, will naturally be more suitable than ordinary
super, and when it is remembered that four-fifths of the former consists of ordinary superphosphate, the manufacturer will find it to his interest to supply the new manure. Indeed, on all light sandy ferruginous
soils manufacturers are at present in an awkward
position, because acid manures being unsuitable it follows that an alkaline manure, superior in its fertiliz ing properties to basic slag, should be supplied, as
otherwise no practical opposition to the use of slag is Basic superphosphate has the advantage that it can be mixed with nitrate of soda without any fear that
the valuable nitric acid will be decomposed or driven off by an excess of acid, and the resulting compound is in an excellent dry powdery condition, admirably
adapted to secure uniform distribution as a top dressing. During the season 1901, the manure has been sold in 187 places in England, 72 in Scotland, and 13 in Iretities of 10 actual local trials have been still more numerous. The practical results obtained in the field have, not withstanding the dry season, been most encouraging,
and have fully realized the favorable opinion originally
formed from the analytical results.

\section{ConcLusion.}

In conclusion, it should be mentioned that basic superphosphate is not intended to supersede ordinary lime, nor is it intended to take the place of well ground slag for application to damp sour land; but
it is rather intended to take an intermediate position between these two well-known and most useful man phosphate manure, specially useful as a spring aline ing for crops grown upon soils that contain less than 1 per cent of lime, the united acreage of which repre-
sents such a large area of the cultivated land in the Sents such a lar

United Kingdom.
The utility of alkaline phosphate manures when applied to certain soils has already been practically demonstrated by the great success that has attended
the use of basic slag, notwithstanding its slow soluthe use of basic slag, notwithstanding its slow solu-
bility, its frequently defective grinding, and recently. its reduced percentage of phosphate.
If therefore a material of similar alkalinity, but of greatly superior solubility, can be obtained in an un-
limited quantity, and of uniform quality, it is reasonable to anticipate that basic superphosphate will prove
to be a really useful and most valuable additional to be a really useful and most valuable adritional
fertilizer. The time has come when manures should be adaptes to the manure.
Obviously, soils differing so much in their chemical peat and sand, granite and gravel, require different 
manures, in the same way as they require different cultivation and different kinds of crops.

It is not scientific, it is not economical, and it canof manure should be sold for application to all kinds of soils.

Acid manures may with advantage be applied wher there is plenty of lime, and alkaline manures may be

SOME LOCOMOTIVE SHOP TOOLS

THE engraving shows a spring testing machine
ade by Joshua Buckton \& Co. of Leeds, which made by Joshua Buckton \& Co., of Leeds, which will not only weigh and measure the eflection of the
spring, but will give it a rapid action such as it spring, but will give it a rapid action such as it
would encounter in running on a permanent way, and will then exactly weigh and measure the falling off in the spring if there should be any. It is designed to test laminated springs, helical springs, and volute springs up to 12 tons pressure, up to 7 feet 6 inches is 15 inches, variable down to 3 inches, and the ram an be driven either at ten strokes a minute for accurately calibrating the resilience of the springs, or the springs to withstand rapid vibrations. The end locomotive fireboxes a special swiveling table is used in conjunction with this machine. There is a pit at the back of the main table, which can be swiveled until it is in a vertical plane like the face plate of a circular motion, controlled by a worm and worm wheel, so that all four sides of a locomotive fire-box can be drilled at one setting of the table. Holes, in while the angle whatever can be drilled in the work The Engineer.

REPORT ON THE METRIC SYSTEM.

THE report of the committee on the bill providing for the adoption of the metric system by the government of the Unite States has been completed. The systems of

complete statement of the weights and measure more space than is available in a brie ous units have been inherited from a time when exact measurements were unheard of, computations were seldom made, and when each locality and different inter est had its own system of measures. Modifications and tems of weight, the apothecary, the troy and the yard may be stated as our standard of length, we tind the yard and foot; for example, the fathom, the surveyors' and en gineers' chains, the nautical and statute miles, hands, poles, perches and various others. In addition to the ordinary cubic measure we find three systems of measuring capacity: dry measure, liquid measure and a large number of technical standards in use in the various trades and industries, which would be greatly simplified and unified upon the adoption of the international system of weights and measures. An ex amination of the common tables of weights and meas ures discloses the fact that there are 64 different ratios used, of which 19 are not divisible by two, and meanings are 18 terms used which have two or more gress to. Certainly any efror on simple, logical one similar to our monetary system is worthy of the consideration of Congress.

The metric system of weights and measures was devise as an international system. The fact that it was first adopted by rane has given rise to the custom of referring to it as the French system. It is interesting to note, however, that one of the lirst to propose a

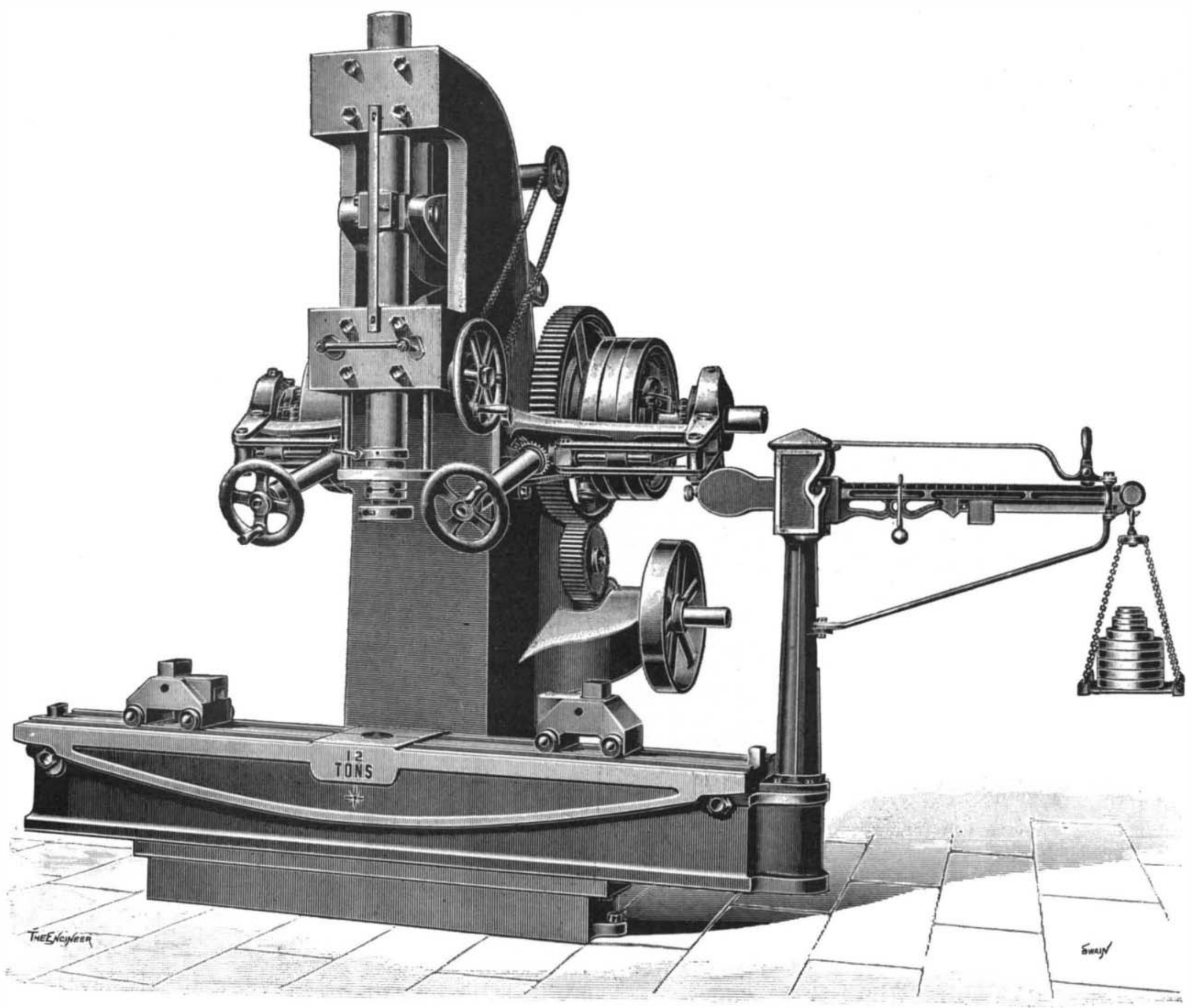

TAFF VALE RAILWAY--SPRING TESTING MACHINE

of the ram is fitted with a screw adjustment to suit ram is arranged to act upon the pressure from the vame in holes, which the weight of the rolling the bears uin holes, which the weight of the rolling stock lets, and other attachments are tested at the same
time as the spring itself. When the machine is testing the springs with its rapid action the spring are made to vibrate through a range of 3 inches or inches without the removal of the load, so that the spring and all its attachments are acted upon with the same violence as they would encounter if runnin fect joints. This marhine is in use at the works of the Taff Vale Railway, Cardiff.

A radial drilling machine for boiler work is shown in another engraving. The special advantage of this machine is that it will drill two holes at a time a any distance from each other between 7 inches and feet. The headstocks carrying the drill spindles have a motion of 14 inches at right angles to the main which may be readily averlooked in the engravin This enables lines of parallel holes to be drilled without swinging the main jib. The spindles are reversmachine are near the end of the jib. For drlllin theless, the system is full of inconsistent ratios, the units are not related to each other, many units of the cifferent values, it is unsuitable for last defect has sometimes been urged in its favor, but the subject should advocate any other than a decima system of weights and measures in connection with decimal system of numbers. It may be true that system of weights and measures in which a binar subdivision is followed might be better in a few in the adves but, on the whole, experience has shown that outweigh those of any other. However, it should be noted that a binary system of subdivision is but seldom followed in our common system of weights an measures, and further that a ecimal system is capable of this metho of subdivision, as illustrate by the us of halves and quarters in the metric system of mea poney.

in a measure not true, as neither our pound, the yard, the gallon bushel are identical.

Very few people are familiar with the weights an measures in common use in the Unite States. On has but to recall the tables of our three different sy
Watt, the inventor of the steam engine, and the adop tion of a decimal system of coinage by the Unite its a was one of the strongest inhuences leading to in the metric system was called the meter and defined as the one ten-millionth part of the distance from the equator to the pole of the earth measured on a merie lan. The first of these units to be constructed was by the French government and was base upon the best known measurements of the earth's surface at that time. Subsequently more accurate measure as first constructed was not sho the lenth intende nor was its material or form such as required by modern refined measurement

To remedy this defect an international congress wa held in Paris, 1875, 17 different nations participating. It was thought best to retain the length of the old meter. Accordingly a number of copies were constructed of the best material and method of constructhe international meter and is very carefully pre served at the International Bureau of Weights and participating in the congress and those which joine the convention later. These meters were very care-
fully compared with the one selected as the inter 